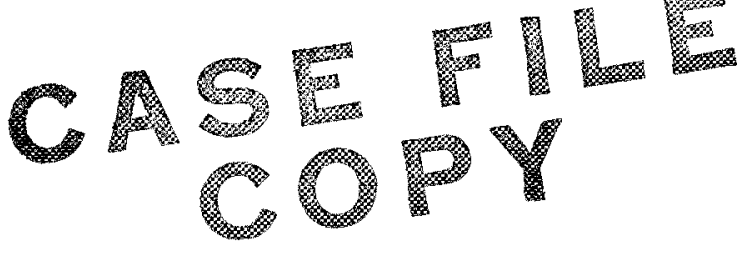

\title{
AN INVESTIGATION OF GRAVITY EFFECTS ON LAMINAR GAS JET DIFFUSION FLAMES
}

by Thomas $\mathrm{H}$. Cochran and William J. Masica Lewis Research Center

Cleveland, Ohio

TECHNICAL PAPER proposed for presentation at 13 th International Symposium on Combustion sponsored by The Combustion Institute Salt Lake City, Utah, August 23-29, 1970 
AN INVESTIGATION OF GRAVITY EFFECTS ON LAMINAR

GAS JET DI FFUSION FLAMES

by Thomas H. Cochran and William J. Masica

Lewis Research Center

Cleveland, Ohio

TECHNI CAL PAPER proposed for presentation at

13th International Symposium on Combustion sponsored by The Combustion Institute Salt Lake City, Utah, August 23-29, 1970 


\title{
AN INVESTIGATION OF GRAVITY EFFECTS ON LAMINAR
}

\author{
GAS JET DIFFUSION FLAMES \\ by Thomas H. Cochran and William J. Masica \\ Lewis Research Center \\ National Aeronautics and Space Administration \\ Cleveland, Ohio
}

\begin{abstract}
SUMMARY
An experimental program was conducted to study the burning of laminar gas jet diffusion flames in a zero gravity environment. The tests were conducted in the Lewis Research Center's 2.2 second zero-gravity facility. The photographic results indicate that a sudden decrease in gravity level from one to zero effected an immediate reduetion in the length of the flame. Continued time in zero gravity resulted in the flame expanding away from the burner. For lower Reynolds number fuel flows, the flames increased in size until they appeared to be extinguished while for high Reynolds number fuel flows they established a steady state zerogravity configuration.
\end{abstract}

\section{INTRODUCTION}

During the last decade, the National Aeronautics and Space Administration has been pursuing research programs studying the effects of gravity on basic fluid mechanics and heat transfer processes. The potential applicability of these studies ranges from static to steady state dynamic situations. One subject area that has received a great deal of attention in more recent years is combustion; more specif- 
ically, diffusion flames. This has resulted from the concern over fires aboard spacecraft and how to control them.

Research conducted to date in this area has concentrated on gravity effects on the burning of solids and liquids. Kumagai and Isoda ${ }^{1}$ observed liquid droplets burning in reduced gravity and concluded that gravity induced convection had a definite effect on the combustion process。 Hall ${ }^{2}$ experimented with a candle burning in a zero gravity environment that was attained by flying an airplane through parabolic trajectories. He concluded that although the geometry of the flame was different in zero gravity as compared to normal gravity, burning continued for the

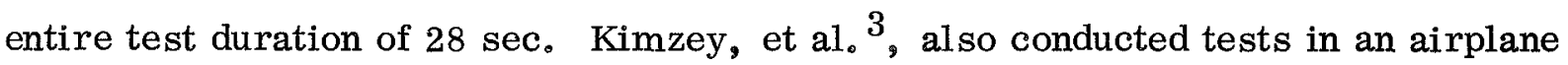
with paraffin and other combustibles and found that for some fuels the flames went out in zero gravity. A recent theoretical study ${ }^{4}$ calculated the extinguishment time for a laminar diffusion flame in zero gravity and obtained satisfactory agreement with the data of Ref. 3. In further zero gravity experimentation in a 2.2 sec drop tower, Andracchio, et al. 5 , burned different solids in an oxygen rich atmosphere. The primary conclusion of this work was that the flame spreading rate in zero gravity was smaller than in normal gravity。

Another diffusion controlled combustion process of interest is the gas jet diffusion flame. The first significant analysis on this type of flame was done by Burke and Schumann ${ }^{6}$ who investigated the problem of fuel flowing from a small-diameter burner tube into air flowing at the same velocity in a larger concentric tube. In their treatment of the problem, they solved only the radial diffusion problem, 
assuming that the gas velocity parallel to the tube axis was constant and ignoring gravity effects. Early work on open jet diffusion flames was done about the same time by Hottel and Hawthorne ${ }^{7}$ and Wohl, Gazley and Kapp ${ }^{8}$. The approach of these investigators differed from that of Burke and Schumann in that they included some fluid momentum transfer effects by using empirical or semi-empirical relationships in fitting theory to experimental data. They implied the gravity dependence of this kind of burning through their general correlation which was in terms of the Grashof number $\left(\rho \mathrm{d}^{3} \beta \mathrm{g} \Delta \mathrm{T} / \mu^{2}\right)$. Recent theoretical work, such as Goldberg and Cheng $^{9}$ and Chervinsky and Timnat ${ }^{10}$, have treated a more general fluid dynamic problem than those of the past, but they have assumed the gravity effects to be negligible. Several other authors, Thomas ${ }^{11}$ and Strehlow ${ }^{12}$, have predicted buoyancy effects on gas jet flames; however, the lack of data in various gravity environments has made it difficult to validate and extend their hypothesis.

This paper presents the results of a continuing research program 13 being conducted in the NASA Lewis Research Center's 2。2-Second Zero Gravity Facility on the effects of gravity on laminar gas jet diffusion flames. Both regular and infrared motion pictures were taken of methane burning in air in normal and zero gravity. Fuel flow rates at the burner ranged from approximately 1 to $9 \mathrm{~cm}^{3} /$ : sec for burners $0.051,0.112,0.186,0.318$, and $0.442 \mathrm{~cm}$ in radius。

\section{APPARATUS AND PROCEDURE}

The zero gravity experiment results were obtained in the drop tower shown in Fig. 1. A very low gravity environment (less than $10^{-5} \mathrm{~g}$ and termed zero gravity 
in this paper) was obtained by allowing the experiment to free fall in an air-drag shield (see fig。2) which in turn fell approximately $23 \mathrm{~m}$. The experiment was prepared on the 5th floor of the tower, hoisted to the 8th floor, and then released. Aluminum spikes mounted on the drag shield embedded in a box of sand in order to effect a relatively low rate of deceleration $(\sim 30 \mathrm{~g})$.

The experiment package is shown in Fig. 3. Its primary components were a combustion chamber, camera, clock, methane flow system, and carbon dioxide flow system. The combustion chamber contained the burner, lighting equipment, baffles, carbon dioxide inlets and the ignition system. The volume of the chamber $(41 \times 41 \times 48 \mathrm{~cm})$ was such that there was over 50 times the amount of air necessary to burn the fuel at the highest flow rate for an expected test time of $10 \mathrm{sec}$. The top of the chamber had holes in it to insure equilization of pressure with the atmosphere during burning. Baffles were used on some tests in order to reduce flickering of the flames. Their effect on the data, as discussed in the results, was concluded to be negligible。 The igniter was a small nicrome wire which drew current from a dc source. The flow of methane to the burner was controlled by a low-flow needle valve and a pressure regulator. Lighting was indirect so that the flames could be photographed against a black backgrotnd. The photographs were taken through one wall of the chamber which was cut away and replaced with plastic sheet. The two types of film used were color and infrared. The color film was high speed $16 \mathrm{~mm}$ Ektachrome EF (Tungsten) manufactured by the Eastman Kodak Co. 
Pictures were taken with this film at an apperature setting of $f-1.1$ and a speed of 400 frames per sec. The color film was processed to an ASA of 250. The infrared film was also a high speed $16 \mathrm{~mm}$ film manufactured by the Eastman Kodak Co. Apperature setting was the same as that for the color film, however, the camera speed was much slower at 5 frames per sec. A filter was not placed on the lens of the camera so that the film recorded visible radiation as well as infrared radiation up to about 9000 Angstroms.

After charging the two gas systems, the experiment package was placed in the drag shield and raised to the top of the tower. Approximately 5 seconds before dropping, the methane flow, ignition, and photographic systems were initiated and a steady-state normal gravity flame was established. After dropping, about 2 sec of zero-gravity data was obtained. Just before impact in the sand, all operating systems were deactivated and carbon dioxide was flowed into the combustion chamber. This was done in order to ensure the safety of the experiment by removing potential ignition sources and diluting a possible combustible mixture. The tests with infrared film were the same as described above except that the plastic wall was removed in order to ensure the unimpaired transmittance of infrared radiation to the camera.

Prior to the normal and zero-gravity experimentation, calibrations to determine flame length as a function of flow rate were conducted. The flow measuring device, a rotometer, was installed in the methane flow system. Motion pictures were then taken of flames at different lengths and the respective flow rates were recorded. 
Data was obtained for each of the different burners over the range of flow to be used in the experiments.

The data recorded on film was viewed on a motion analyzer. In addition to generally observing the phenomena, measurements of flame length as a function of time were made, A scale factor for the flame length measurements was obtained from the burner diameter.

\section{RESULTS}

Low Reynolds Number Fuel Flows

The normal gravity calibrations to establish the relationship between flame length and flow rate for Reynolds numbers $\left(\rho_{F} \mathrm{U}_{\infty} \mathrm{R}_{\mathrm{o}} / \mu_{\mathrm{F}}\right)$ between 65 and 540 is presented in Fig. 4. The linear relationship apparent in the data is in agreement with the findings of previous investigators such as Wohl, et $2 l^{8}$. There is little scatter in the data at the smaller flow rates; however, it becomes more severe at the larger values. This is attributed to flickering or pulsating of the flame. In all but three tests (normal and zero gravity included) the amplitude of the oscillations was less than $\pm 5 \%$ of the average length. The maximum amplitude was $\pm 7 \%$ of the average length.

The effects of zero gravity on gas jet diffusion flames at low fuel Reynolds numbers is best described by reference to Fig. 5. As can be seen, the flames experienced an immediate reduction in length after which they expanded away from the burner both axially and radially until extinguishment appeared to occur. In general, the time required for a flame to disappear depended on the burner size and flow rate. The color of the flames in normal gravity was basically yellow with a slight 
blue tinge near the burner. In zero gravity, the color changed from yellow to orange to dark orange before disappearing. No blue at all was visible in zero gravity. The infrared films, which were more sensitive to cooler temperatures than the color films, indicated similar results, A particular effect apparent in these films occured at the burner where it appeared that in zero gravity the hot gases expanded perpendicular to the axial flow after the initial reduction in length. The fact that the flames disappeared on the infrared films also suggests that they were extinguished,

Two flame characteristics that were specifically noted on the color film for each test were the minimum zero gravity length and the extinguishment length. The latter was defined as that distance from the burner where the top of the flame was last vi sible, A compliation of all the low Reynolds number data is made in table I. The flow rate for each run was determined from Fig. 4 and the measured normal gravity length.

Comparison of the minimum zero gravity length for the different burners as a function of flow rate is made in Fig. 6. Also plotted on the graph is the normal gravity curve obtained from Fig. 4. It is apparent that at small values of flow rate the minimum zero gravity length for all the burners approaches the normal gravity length. As flow rate is increased, the difference between the normal and zero gravity data increases and is a function of the burner size. The data indicate a greater reduction for a given flow rate as burner size increases. This effect is probably caused by the fact that as burner size increases for a given flow rate the 
average velocity of the exiting gases decreases. This means that the importance of inertia in driving the gases downstream of the burner also decreases.

In Fig. 6, the solid data points denote tests that were conducted without baffles. This, of course, was done for the smaller flames where oscillation was not a problem. The data indicate that the results from the tests run without baffles are in agreement with those run with baffles. Similar results were found for the extinguishment length data. Therefore, it was concluded that the effect of the baffles on behavior of the smaller flames in zero gravity was negligible. The fact that the trends in the data substantiated by the smaller flames continued for the larger flames and that the flames did not approach the baffles as seen in the color films, suggest that the effect of the baffles on all the data was small.

High Reynolds Number Fuel Flows

The tests at high fuel Reynolds numbers were conducted with no baffles, with the two smaller burners (0.051 and $0.112 \mathrm{~cm}$ in radius), and at Reynolds numbers up to approximately 3500. Quantitative data is not available at the writing of this paper, however, qualitative results can be presented.

As can be seen in Fig. 7, these flames also became smaller immediately upon entering zero gravity. However, a significant difference as compared to the low Reynolds number data was that instead of expanding away from the burner and disappearing, these flames expanded to a length greater than the original normal gravity length where they stablized for the remaining time in zero gravity. There 
was a great deal more carbon particle radiation in the stable zero gravity flame than in its normal gravity counterpart and it appeared to be more yellow.

It was stated previously that these tests were conducted without the baffles. Consequently, the normal gravity flames had a tendency to oscillate, particularly the larger ones which were up to $9 \mathrm{~cm}$ in length. In zero gravity, these same flames become very steady with little or no pulsating at all.

These results, together with the low Reynolds number data, indicate that a particular set of flow conditions are necessary in order for a gas jet flame to exist in a zero gravity environment. Continued work to reduce the high Reynolds number data should yield this critical condition.

\section{DISCUSSION OF RESULTS}

The physics of a laminar gas jet diffusion flame are complex, and in many parts, undefined, even without considering the gravity effects. For instance, the fluid dynamics of a low velocity free jet issuing into the same medium is not even adequately understood at this date. Therefore, the objective of this paper is not to attempt a complete solution of the problem, but rather, to concentrate on the possible effects gravity could have on the aerodynamics of laminar jet flames.

Consider a flame attached to a simple tube type burner out of which fuel is flowing verticąlly into an atmosphere of air. Experimental data, such as in Wolf-

$\operatorname{hard}^{14}$, indicate that the hottest region of the flame is in the reaction zone. Therefore, on the oxidant side of the reaction zone, the temperature gradient is in the opposite direction as the acceleration due to gravity, thus, creating a buoyant 
effect. The equation, in cylindirical coordinates governing the axial motion of fluid exterior to the reaction zone is

$$
\rho \mathrm{u} \frac{\partial \mathrm{u}}{\partial \mathrm{z}}+\rho \mathrm{v} \frac{\partial \mathrm{u}}{\partial \mathrm{r}}=\rho \Delta \mathrm{T} \beta \mathrm{g}+\frac{1}{\mathrm{r}} \cdot \frac{\partial}{\partial \mathrm{r}}\left(\mu \mathrm{r} \frac{\partial \mathrm{u}}{\partial \mathrm{r}}\right)
$$

This boundary layer equation is the same as that used in Refs. 9 and 10, with the addition of gravitational terms. Nondimensionalization of this equation with respect to characteristic values results in

$$
\left(\frac{\rho_{\mathrm{M}}^{2} \mathrm{U}_{\infty}^{2} \mathrm{R}_{\mathrm{o}}^{2}}{\mu_{\mathrm{M}}^{2}}\right) \bar{\rho}\left(\overline{\mathrm{u}} \frac{\partial \overline{\mathrm{u}}}{\partial \overline{\mathrm{z}}}+\overline{\mathrm{v}} \frac{\partial \overline{\mathrm{u}}}{\partial \overline{\mathrm{r}}}\right)=\left(\frac{\rho_{\mathrm{M}}^{2} \Delta \mathrm{T}_{\mathrm{AF}} \mathrm{M}_{\mathrm{M}} \mathrm{gR}_{\mathrm{o}}^{3}}{\mu_{\mathrm{M}}^{2}}\right) \bar{\rho} \Delta \overline{\mathrm{T}} \bar{\beta}+\left(\frac{\rho_{\mathrm{M}} \mathrm{U}_{\infty}^{\mathrm{R}} \mathrm{o}}{\mu_{\mathrm{M}}}\right) \frac{1}{\overline{\mathrm{r}}} \frac{\partial}{\partial \overline{\mathrm{r}}}\left(\bar{\mu} \overline{\mathrm{r}} \frac{\partial \overline{\mathrm{u}}}{\partial \overline{\mathrm{r}}}\right)
$$

The air and products of combustion are driven in the axial direction by buoyancy and inertia. The latter is derived from momentum transfer from the fuel flow inside the reaction zone. As would be expected, the Grashof number characterizes the buoyancy effects while the Reynolds number squared is representative of the inertia effects.

The buoyancy influence on the convective motion can affect the flame in at least two ways. The first and most obvious effect is through the diffusive motion of the oxidant. Since the diffusion equation contains convection terms, the concentration profile for the oxidant in the flow field will depend on buoyancy. Further, the criteria for the position of the reaction zone is that the rate at which the oxidant and fuel arrive at the zone be in stoichiometric ratio. Therefore, because convection affects the rate of oxidant diffusion, the geometry of flames depends on 
gravitational effects. The axial position in the vicinity of the flame where these buoyant effects should be the strongest is at the flame tip. At this point, buoyancy has increased the momentum of the hot gases over the longest distance. This explains the initial reduction in length of the flames that was evident in all the data. Another factor that affects the oxidant diffusion is the concentration of the products of combustion in the flow field. Since the motion of the products of combustion and hence, the concentration, is dependent on convection, gravity again affects the diffusive motion of the oxidant and ultimately, the geometry of the flame. This explains the expansion of the flames after their initial reduction in length. Without buoyancy to aid in cleansing the flame of the products of combustion, the fuel must travel further from the burner in order to meet sufficient oxidant for a reaction to exist.

\section{Correlations}

Percent decrease in the length of a flame when it is suddenly placed in a zero gravity environment was selected to be a measure of the importance gravity plays in the aerodynamics of normal gravity jet diffusion flames. The percent decrease is defined as $\left(L_{1}-L_{0}\right) / L_{1}$ where $L_{1}$ is the normal gravity length and $L_{0}$ is the minimum zero gravity length. In seeking a correlation for this parameter, it should be recalled that the data indicated that both buoyancy, or the lack of it, and inertia affected the dynamics of the flames. Accordingly, a correlation in terms of the Grashof and Reynolds numbers as defined in Eq. (2) was determined. In evaluating the parameters, the fluid properties are assumed to be approximately 
equal to those for air. The results for the low fuel flows are shown in Fig. 8. The least-squares line through the data has the equation

$$
\frac{\mathrm{L}_{1}-\mathrm{L}_{\mathrm{O}}}{\mathrm{L}_{1}}=0.09\left(\mathrm{Gr}^{0.37} \mathrm{Re}^{0.69}\right)_{\mathrm{A}}
$$

A correlation for the dimensionless extinguishment length, defined as $L e / R_{0}$ was found in terms of the Reynolds number of the fuel, $\mathrm{Re}_{\mathrm{F}}$. These results are shown in Fig. 9.

\section{CONCLUSION}

An experimental program was conducted in which a drop tower was used to obtain zero gravity data for laminar gas jet diffusion flames. Motion picture photographs were taken of methane burning in quiescent air for various flow rates and burner sizes. The results indicated that a sudden decrease in gravity level from one to zero effected an immediate reduction in the length of the flames. This was attributed to the buoyancy of the oxidant surrounding the reaction zone in normal gravity and the subsequent lack of buoyancy in zero gravity. A correlation for the percentage decrease in the flame length was obtained in terms of the Grashof and Reynolds numbers evaluated for air at a mean condition between the adiabatic flame temperature and the ambient air temperature. The correlation is

$$
\text { Percent decrease }=\frac{L_{1}-L_{O}}{L_{1}}=0.09\left(\mathrm{Gr}^{0.37} \mathrm{Re}^{0.69}\right)_{\mathrm{A}}
$$

Continued exposure of the flames to zero gravity resulted in the flames expanding away from the burner. This expansion was concluded to be caused by the accumulation of the products of combustion about the flames. For low Reynolds number 
fuel flows, the flames increased in size until they appeared to be extinguished while for high Reynolds number fuel flows, they established a steady-state zero gravity configuration.

\section{NOMENCLATURE}

d characteristic length, $\mathrm{cm}$

Gr Grashof number, $\left(\rho^{2} \Delta \mathrm{T} \beta \mathrm{g} \mathrm{d}^{3} / \mu^{2}\right)$

g acceleration of gravity, $\mathrm{cm} \mathrm{sec}{ }^{2}$

$\mathrm{L}_{\mathrm{e}} \quad$ extingui shment length, $\mathrm{cm}$

$\mathrm{L}_{\mathrm{o}} \quad$ zero gravity minimum flame length, $\mathrm{cm}$

$\mathrm{L}_{1} \quad$ normal gravity flame length, $\mathrm{cm}$

$R_{0} \quad$ burner radius, $\mathrm{cm}$.

Re Reynolds number, $\left(\rho \mathrm{U}_{\infty} \mathrm{d} / \mu\right)$

$\mathrm{T}_{\mathrm{AF}} \quad$ adiabatic flame temperature, ${ }^{\circ} \mathrm{C}$

$\mathrm{T}_{\mathrm{AM}}$ ambient air temperature, ${ }^{\circ} \mathrm{C}$

${ }^{\mathrm{T}_{\mathrm{M}}}$ mean temperature $-1 / 2\left(\mathrm{~T}_{\mathrm{AF}}+\mathrm{T}_{\mathrm{AM}}\right),{ }^{\mathrm{o}} \mathrm{C}$

$\Delta \mathrm{T}_{\mathrm{AF}} \quad \mathrm{T}_{\mathrm{AF}}-\mathrm{T}_{\mathrm{AM}},{ }^{\circ} \mathrm{C}$

$\Delta \mathrm{T} \quad$ temperature difference $\mathrm{T}-\mathrm{T}_{\mathrm{AM}},{ }^{\mathrm{O}} \mathrm{C}$

$\mathrm{U}_{\infty} \quad$ average axial fuel velocity at burner, $\mathrm{cm} / \mathrm{sec}$

u axial velocity, $\mathrm{cm} / \mathrm{sec}$

$\mathrm{v}$ radial velocity, $\mathrm{cm} / \mathrm{sec}$

z axial dimension, $\mathrm{cm}$

$\rho \quad$ density, $\mathrm{kg} / \mathrm{m}^{3}$ 
$\beta \quad$ coefficient of thermal expansion

$\mu \quad$ dynamic viscosity, $\mathrm{kg} / \mathrm{cm}-\mathrm{sec}$

Symbols with bars denote dimensionless quantities

Subscripts

M mean temperature condition $\mathrm{T}_{\mathbf{M}}$

F fuel

A air

\section{REFERENCES}

1. Kumagai, S. and Isoda, $\mathrm{H}_{\circ}$ : Sixth Symposium (International on Combustion, p. 726, Williams \& Wilkins, 1956.

2. Hall, A. L.: Observations on the Burning of a Candle at Zero Gravity, Naval School of Aviation Medicine Report 5, AD-436897, February 1964.

3. Kimzey, J. H., Downs, W. R., Eldred, C. H., and Norris, C. W.: Flammability in Zero-Gravity Environment, NASA TR R-246, 1966.

4. Atallah, S., Bonne, U., and deRis, J. N.: The Flammability of Electronic Components in Spacecraft Environments, Factory Mutual Research Corp., NASA CR-86106, October 1968.

5. Andracchio, C. R. and Aydelott, J.C.: A Comparison of Flame Spreading Over Thin Flat Surfaces in Normal Gravity and Weightlessness in a 5 psia Oxygen Environment, proposed NASA Technical Memorandum.

6. Burke, S. P. and Schumann, T. E. W.: Ind. Eng. Chem. 20,998 (1928). 
7. Hottel, H. C. and Hawthorne, W. R.: Third Symposium on Combustion and Flame and Explosion Phenomena, p. 288, Williams \& Wilkins, 1949.

8. Wohl, K., Gazley, C., and Kapp, N. M.: Third Symposium on Combustion and Flame and Explosion Phenomena, p. 288, Williams \& Wilkins, 1949.

9. Goldburg, A. and Cheng, S. -I: Combustion and Flame $\underline{9}, 259$ (1965).

10. Chervinsky, A, and Timnat, Y, M.: On the Distribution of Momentum Heat and Matter in Axisymmetrical Jet Diffusion Flames, Israel. Institute of Technology TAE Report No. 62, 1967.

11. Thomas, P. H.: Combustion and Flame $\underline{4}, 381$ (1960).

12. Strehlow, R. A.: Fundamentals of Combustion, International Textbook, 1968.

13. Cochran, T. H. and Masica, W. J.: Effects of Gravity on Laminar Gas Jet Diffusion Flames, proposed NASA Technical Note.

14. Wolfhard, H. G. and Parker, W. G.: Proc. Phys. Soc. A65, 2 (1952).

15. Schlichting, H.: Boundary Layer Theory, Fourth Ed., McGraw-Hill, 1960. 
TABLE I. - TEST DATA FOR LOW REYNOLDS NUMBER FUEL FLOWS

\begin{tabular}{|r|c|c|c|c|c|c|}
\hline Run & $\begin{array}{c}\text { Normal } \\
\text { gravity } \\
\text { length, } \\
\text { cm }\end{array}$ & $\begin{array}{c}\text { Flow rate, } \\
\text { cc/sec }\end{array}$ & $\begin{array}{c}\text { Nozzle } \\
\text { radius, } \\
\text { cm }\end{array}$ & $\begin{array}{c}\text { Velocity, } \\
\text { cm/sec }\end{array}$ & $\begin{array}{c}\text { Zero gravity } \\
\text { minimum } \\
\text { length, } \\
\text { cm }\end{array}$ & $\begin{array}{c}\text { Extinguish- } \\
\text { ment } \\
\text { length, } \\
\text { cm }\end{array}$ \\
\hline 1 & 1.46 & 1.6 & 0.186 & 14.73 & 1.18 & 1.58 \\
2 & 4.19 & 4.04 & .186 & 36.87 & 2.53 & 4.59 \\
3 & 2,78 & 2.80 & .186 & 25.44 & 1.86 & 2.93 \\
4 & 5.60 & 5.30 & .186 & 48.31 & 3.35 & 6.63 \\
5 & 4.80 & 4.56 & .186 & 41.82 & 2.88 & 5.20 \\
6 & 1.02 & 1.22 & .186 & 11.16 & .87 & 1.07 \\
7 & 2.02 & 2.12 & .186 & 19.40 & 1.48 & 1.96 \\
8 & 2.36 & 2.42 & .186 & 22.14 & 1.73 & 2.53 \\
9 & 2.84 & 2.84 & .318 & 8.97 & 1.64 & 2.50 \\
10 & 3.96 & 3.83 & .318 & 12.10 & 2.04 & 3.50 \\
11 & 5.16 & 4.89 & .318 & 15.48 & 2.57 & 4.52 \\
12 & 1.35 & 1.51 & .318 & 4.77 & 1.03 & 1.32 \\
13 & 1.53 & 1.68 & .318 & 5.28 & 1.12 & 1.47 \\
14 & 2.04 & 2.13 & .318 & 6.76 & 1.35 & 1.92 \\
15 & 2.49 & 2.53 & .318 & 7.99 & 1.50 & 1.32 \\
16 & 1.89 & 2.00 & .318 & 6.32 & 1.29 & 1.76 \\
17 & 3.24 & 3.20 & .442 & 5.22 & 1.74 & 2.96 \\
18 & 1.28 & 1.45 & .442 & 2.36 & .95 & 1.26 \\
19 & 2.09 & 2.18 & .442 & 3.55 & 1.30 & 1.96 \\
20 & 4.24 & 4.08 & .442 & 6.65 & 2.08 & 3.78 \\
21 & 2.86 & 2.85 & .442 & 4.64 & 1.54 & 2.46 \\
22 & 3.15 & 3.13 & .442 & 5.10 & 1.71 & 2.69 \\
23 & 2.68 & 2.70 & .442 & 4.40 & 1.56 & 2.18 \\
24 & 1.58 & 1.73 & .442 & 2.82 & 1.12 & 1.43 \\
\hline
\end{tabular}




\section{FIGURE CAPTIONS}

Figure

1

2

3

4

5

6

7

8

9

Title

2. 2 Second zero gravity facility.

Schematic drawing showing position of experiment package before, during, and after test drop.

Experiment package.

Flame length in normal gravity for low Reynolds number fuel flows.

Effect of gravity on gas jet diffusion flame geometry. Run no. 3, flow rate $=2.8 \mathrm{cc} / \mathrm{sec}$, nozzle radius $0.186 \mathrm{~cm}, \operatorname{Re}_{\mathrm{F}}=285 . \quad(\mathrm{a}=$ normal gravity, $\mathrm{b}-\mathrm{f}=$ zero gravity. )

Flame length as a function of flow rate in normal and zero gravity for low Reynolds number fuel flows.

Effect of gravity on gas jet diffusion flame geometry. Estimated flow rate $-1.9 \mathrm{cc} / \mathrm{sec}$, nozzle radius $=$ $0.05 \mathrm{~cm}, \operatorname{Re}_{F}=710$. $(a=$ normal gravity, $\mathrm{b}-\mathrm{f}=$ zero gravity.)

Effects of gravity induced momentum on flame length for low Reynolds number fuel flows.

Dimensionless extinguishment length as a function of gas jet Reynolds number. 


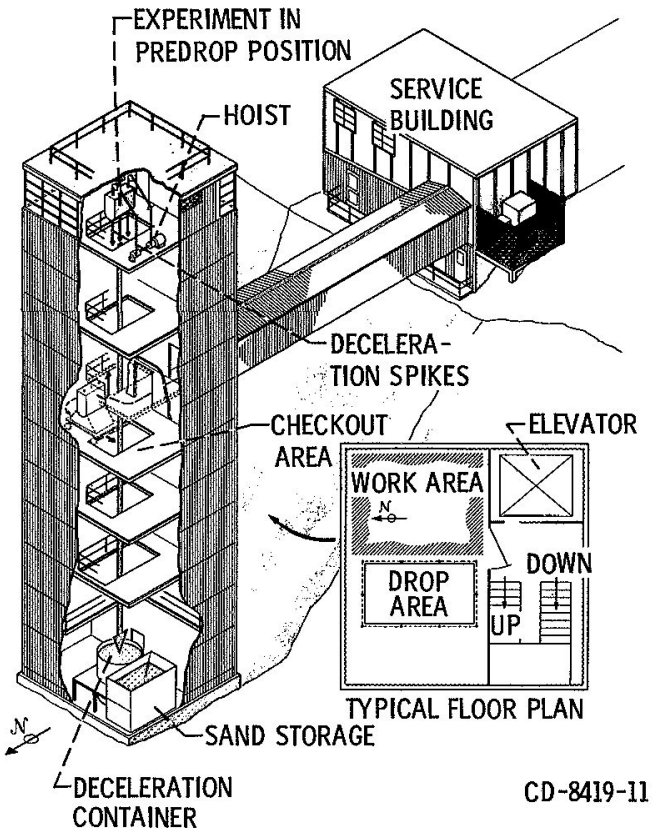

Figure. 1. - 2.2 Second zero gravity facility.

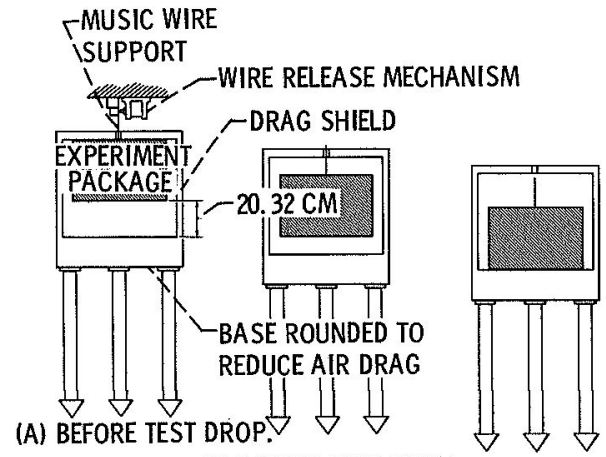

(B) DURING TEST DROP.

CD-10595-11

(C) AFTER TEST DROP.

Figure 2. - Schematic drawing showing position of experiment package and drag shield before, during, and after test drop. 


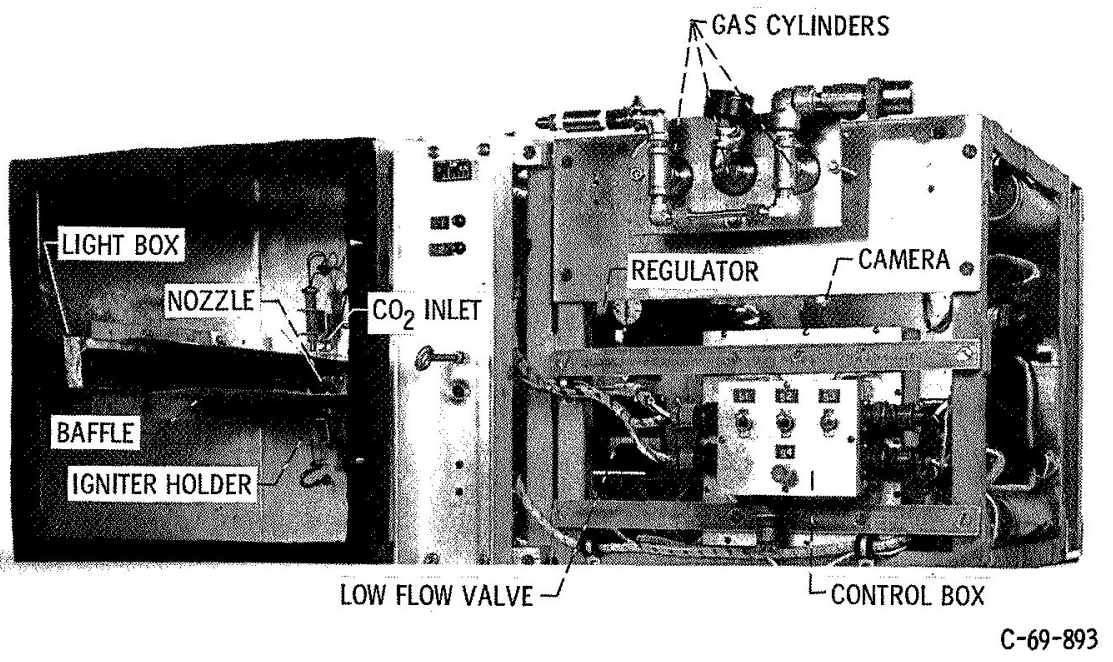

Figure 3. - Experiment package.

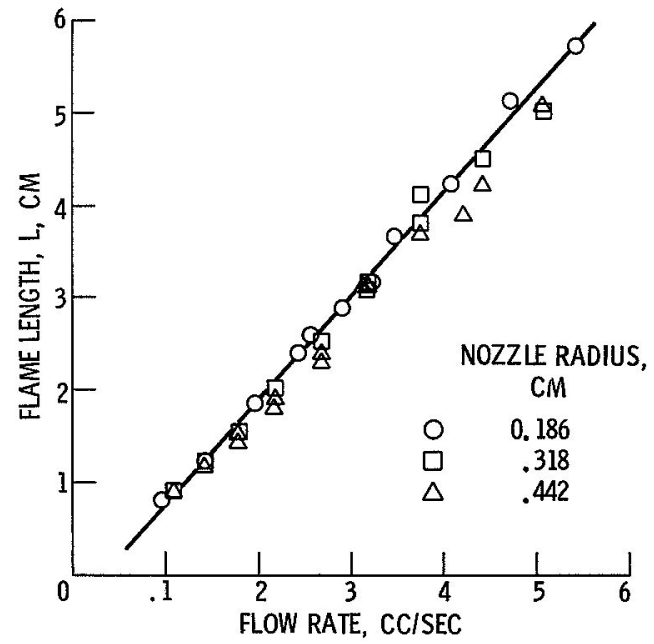

Figure 4. - Flame length in normal gravity for low Reynolds number fuel flows. 


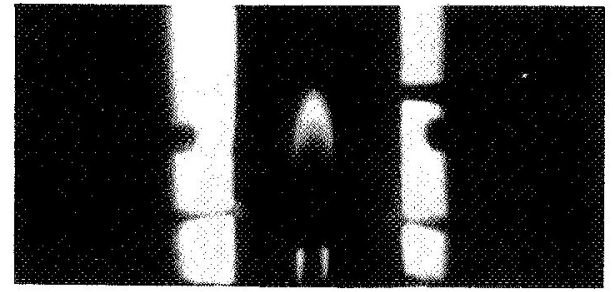

(a) 0 Seconds.

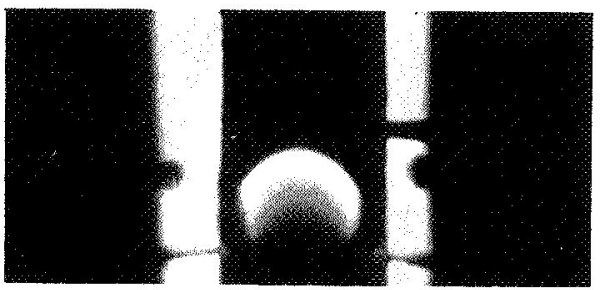

(c) 0.19 Seconds.

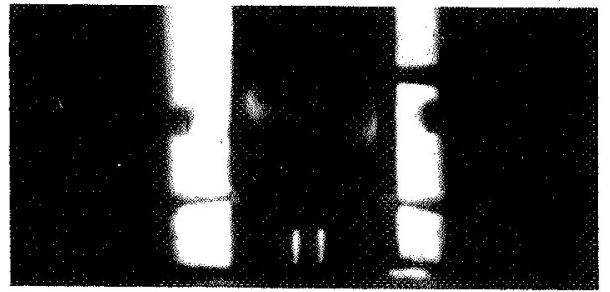

(e) 0.55 Seconds.

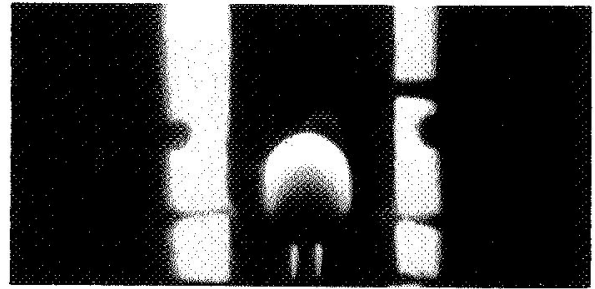

(b) 0.05 Seconds.

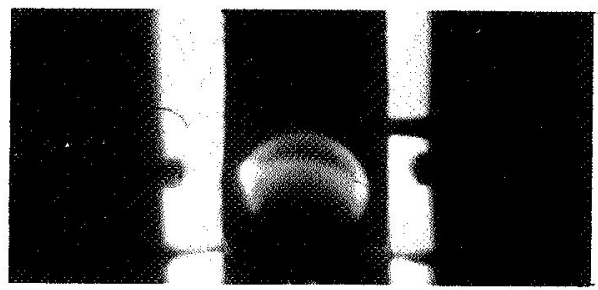

(d) 0.29 Seconds.

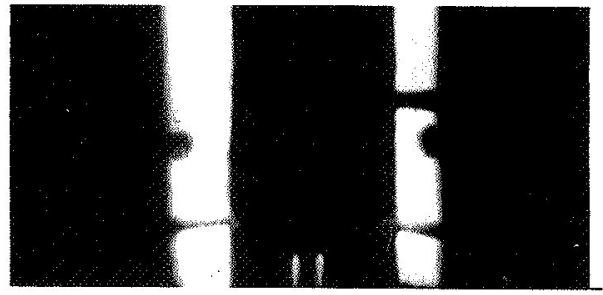

(f) 0.71 Seconds.

Time in zero gravity.

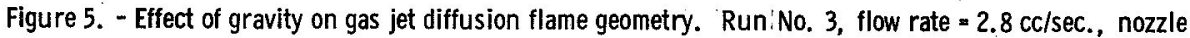
radius $=0.186 \mathrm{~cm}\left(R_{F}=285\right)$.

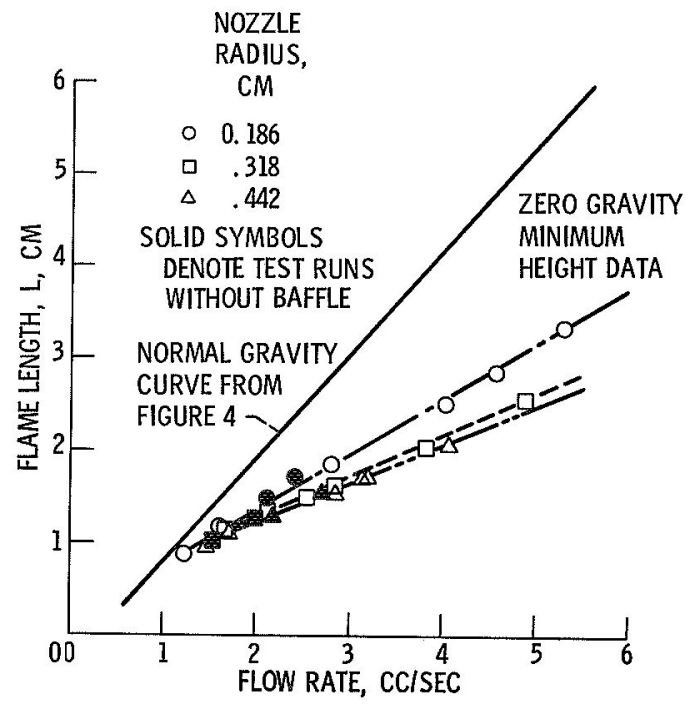

Figure 6. - Flame length as a function of flow rate in normal and zero gravity for low Reynolds number fuel flows. 


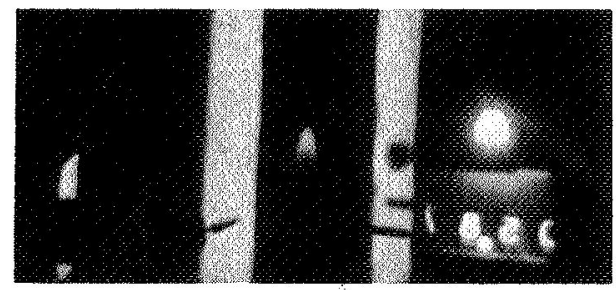

(a) 0 Seconds.

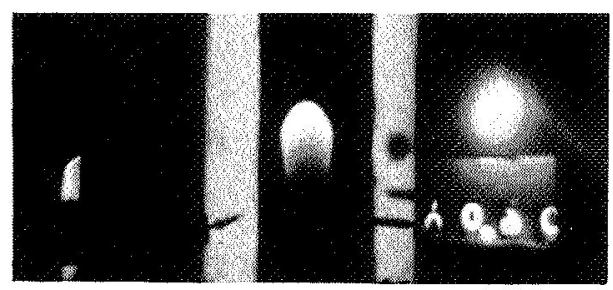

(c) 0.13 Seconds.

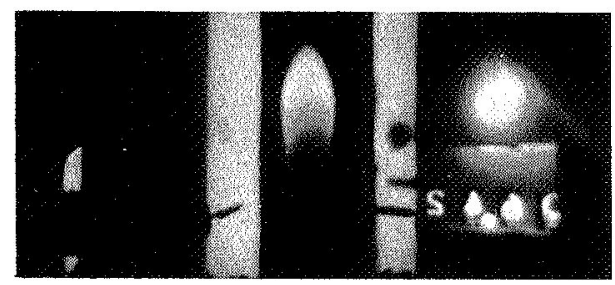

(e) 0.55 Seconds.

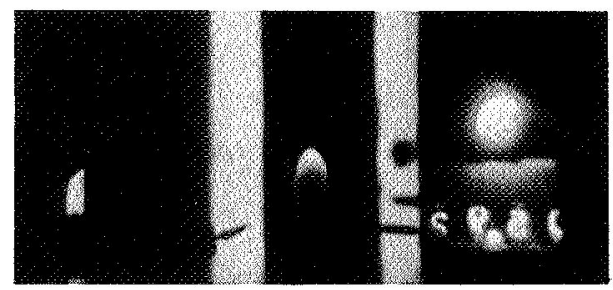

(b) 0.05 Seconds,

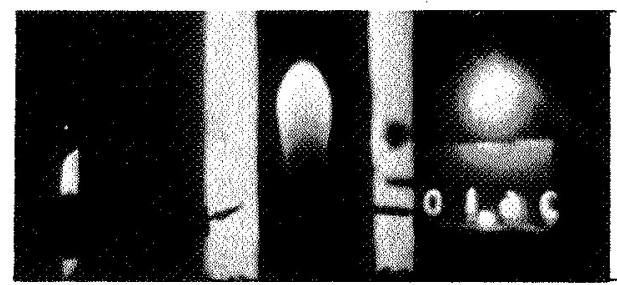

(d) 0.23 Seconds.

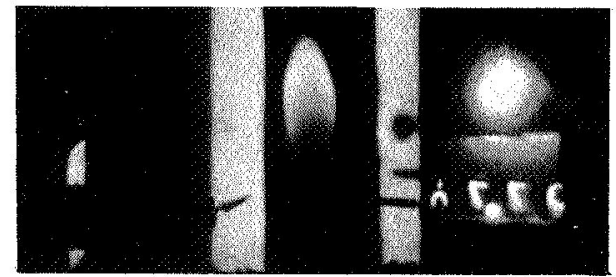

(f) 1.83 Seconds.

Time in zero gravity.

Figure 7. - Effect of gravity on gas jet diffusion flame geometry. Esti mated flow rate $\cong 1.9 \mathrm{cc} / \mathrm{sec}$., nozzle radius $=0.05 \mathrm{~cm}\left(\mathrm{Re}_{\mathrm{F}}=710\right)$. ( $\mathrm{a}=$ normal gravity, $\mathrm{b}-\mathrm{f}=$ zero gravity).

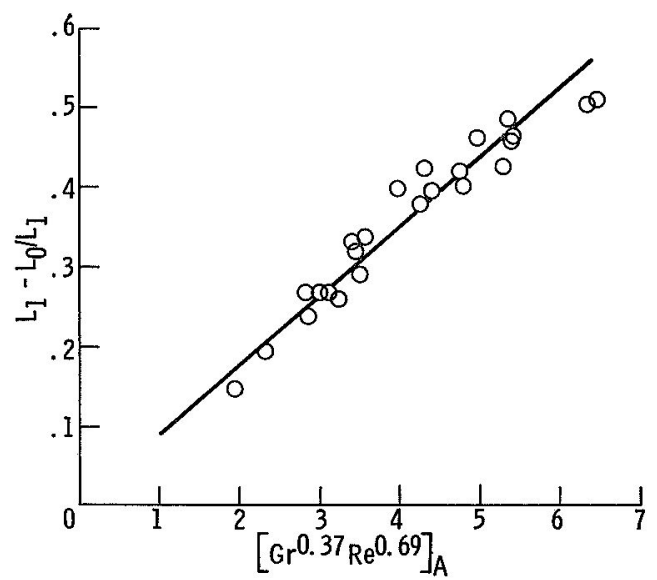

Figure 8. - Effects of gravity induced momentum on flame length for low Reynolds number fuel flows. 


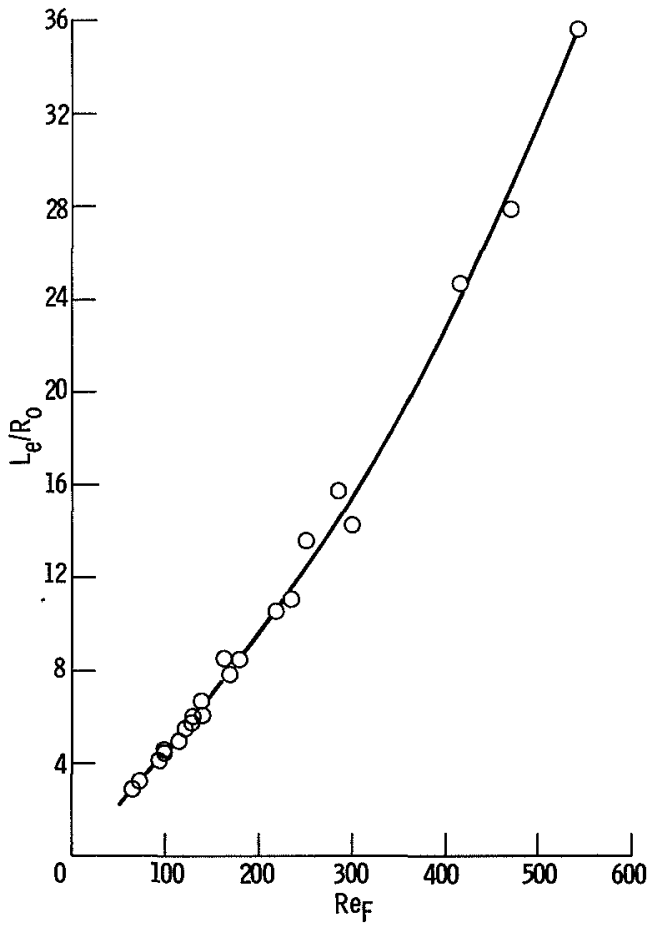

Figure 9. - Dimensionless extinguishment length as a function of gas jet Reynolds number. 